\title{
Serum bilirubin level is associated with diabetic control in type 2 diabetes mellitus
}

\author{
Erkus E*, Aktas G, Kocak MZ, Duman TT and Atak BM \\ Abant Izzet Baysal University Hospital, Department of Internal Medicine, Bolu, Turkey
}

\begin{abstract}
Aim: Type 2 Diabetes mellitus (DM) is a devastating chronic metabolic disorder that associated with cardiovascular diseases. Bilirubin is a natural anti-oxidant of the body which has protective effects against certain conditions. We aimed to compare serum bilirubin levels of well controlled diabetic subjects to those of patients with poorly controlled type 2 DM.

Method: We retrospectively analyzed data of subjects with type 2 DM that presented to our clinic. Patients grouped as well or poorly controlled diabetics according to $\mathrm{HbA1c}$ level.

Result: Serum bilirubin of well controlled and poorly controlled subjects were 1,26 $\pm 0,13 \mathrm{mg} / \mathrm{dl}$ and $0,92 \pm 0,1 \mathrm{mg} / \mathrm{dl}$, respectively. The bilirubin difference was statistically significant $(\mathrm{p}<0.001)$.

Conclusion: Low serum bilirubin levels in type 2 diabetic subjects should alert physicians for worse regulation. In addition to HbA1c measurement, evaluation of serum bilirubin may be useful in follow up of diabetic population.
\end{abstract}

\section{Introduction}

Type 2 Diabetes mellitus (DM) is a devastating chronic metabolic disorder that associated with cardiovascular diseases. It is a condition that characterized with chronic low-grade inflammation which cause depletion in antioxidant capacity of the body.

Bilirubin is a natural anti-oxidant of the body which has protective effects against certain conditions [1]. Antioxidant capacity of serum bilirubin is believed to be beneficial in macrovascular diseases [2].

Since both type $2 \mathrm{DM}$ and cardiovascular diseases are associated with chronic inflammation, we hypothesized that serum bilirubin levels could be related to the diabetic control level, even within normal range. Therefore, in present retrospective study, we aimed to compare serum bilirubin levels of well controlled diabetic subjects to those of patients with poorly controlled type $2 \mathrm{DM}$.

\section{Method}

Subjects with type $2 \mathrm{DM}$ whom presented to internal medicine clinics of our institution between October 2017 and February 2018 were enrolled to the study. Patients' characteristics and laboratory data were recorded from patients' files database of our institution. Study population grouped into two according to the glycated hemoglobin (HbA1c) level. Subjects with an HbA1c level over 7\% were grouped as poorly controlled and lower than $7 \%$ were grouped as well controlled type 2 DM. Patients with advanced chronic renal disease, heart failure, pregnancy, cancer and liver diseases were excluded. Subjects with active infectious or inflammatory disease were also not included to the study.

Age, gender, height, weight, waist circumference, systolic and diastolic pressures and laboratory data, such as, fasting blood glucose, $\mathrm{HbAlc}$, serum total bilirubin, serum creatinine levels were obtained from database and recorded. A body mass index (BMI) was calculated by division of weight in kilograms by the square of height in meters.
Data was analyzed by SPSS software (SPSS 15.0 for Windows, IBM, Chicago, IL, USA). Distribution of variables was conducted by Kolmogorov-Smirnov test. Variables with normal distribution were expressed as mean \pm SD and compared by independent samples $t$ test. Variables without normal distribution were expressed as median (minmax) and compared by Mann Whitney $U$ test. Correlation between study variables was done with Pearson's Correlation analyze. The $\mathrm{p}$ value lower than 0.05 was considered as statistically significant.

\section{Result}

Study population was consisted of 215 type 2 diabetic subjects; 94 in well controlled and 121 in poorly controlled groups. Mean age of the well-controlled and poorly controlled diabetic subjects was $60.2 \pm 12$ years and $58 \pm 11$ years, respectively. Age difference between groups was not statistically significant ( $\mathrm{p}=0.12$ ). There were 46 women and 48 men in well controlled and 55 women and 66 men in poorly controlled diabetic groups. Sex difference between groups was not significant $(\mathrm{p}=0.61)$. Systolic blood pressure $(\mathrm{p}=0.07)$, diastolic blood pressure $(0.84)$, and height $(p=0.50)$ were not statistically different between well controlled and poorly controlled diabetic subjects.

Fasting blood glucose $(\mathrm{p}<0.001)$, serum creatinine $(\mathrm{p}=0.02)$, waist circumference $(p<0.001)$, weight $(p=0.03)$, BMI $(p=0.01)$ and HbAlc $(\mathrm{p}<0.001)$ were significantly lower in well controlled diabetics compared to poorly controlled subjects.

${ }^{\star}$ Correspondence to: Erkus E, Abant Izzet Baysal University Hospital, Department of Internal Medicine, Golkoy, 14280, Bolu, Turkey, Tel: +903742534656; Fax: +903742534615; E-mail: dr.ediperkus@gmail.com

Key words: type 2 diabetes mellitus, bilirubin, $\mathrm{HbAlc}$

Received: May 02, 2018; Accepted: May 22, 2018; Published: May 25, 2018 
Serum bilirubin of well controlled and poorly controlled subjects were $1.26 \pm 0.13 \mathrm{mg} / \mathrm{dl}$ and $0.92 \pm 0.1 \mathrm{mg} / \mathrm{dl}$, respectively. The bilirubin difference was statistically significant $(\mathrm{p}<0.001)$.

In Pearson's correlation analyze, serum bilirubin was significantly and inversely correlated with BMI $(\mathrm{r}=-0.139, \mathrm{p}=0.04)$, waist circumference $(r=-0.195, p=0.004)$, fasting blood glucose $(r=-0,427$, $\mathrm{p}<0.001)$ and $\mathrm{HbAlc}(\mathrm{r}=-0,724, \mathrm{p}<0.001)$.

\section{Discussion}

Main finding of present study is that elevated bilirubin levels are associated with better control in type $2 \mathrm{DM}$ patients who are otherwise healthy.

Association between serum bilirubin and cardiovascular outcomes have been studied for more than two decades. The first study about the topic was by Schwertner et al, which reported negative correlation between bilirubin in blood flow and coronary artery disease [2]. Following studies were confirmed their results by revealing inverse association between circulating bilirubin levels and stroke [3], ischemic heart disease [4], intermittent claudication [5], and coronary calcification [6]. Moreover, it has been proposed as a better predictor of heart disease than HDL-cholesterol [7]. Rate of cardiovascular diseases increases in uncontrolled type $2 \mathrm{DM}$, thus, lower levels of serum bilirubin in poorly controlled subjects in present study is not surprising.

Chronic oxidative stress causes worse diabetic control via defective insulin secretion and gene expression [8]. In 1993, Wolff suggested that diabetes mellitus was linked to the increased oxidative stress [9]. Another study revealed that micro and macrovascular complications of diabetes mellitus were strongly correlated with oxidative stress [10]. Bilirubin is an endogenous antioxidant and decrease the levels of free oxygen radicals, thus, ameliorate oxidative stress [11]. Therefore, free oxygen radicals may increase by lowering of bilirubin levels, thus, causing worse diabetic regulation.

Hyperglycemia in type $2 \mathrm{DM}$ is supposed as the main cause of diabetic complications. Glycation of serum proteins, which increase in hyperglycemic states, may have important role in such conditions. Bilirubin should play important role in preventing glycation of proteins. This hypothesis could explain the association between worse diabetic regulation and lower levels of bilirubin in present study. Strong inverse correlation between fasting plasma glucose and serum bilirubin levels in present study suggests these literature knowledge.

Limitations of present study make our results difficult to interpret in clinical use. One of these limitations is relatively small study cohort. Another limitation is retrospective design of the study. However, to our knowledge, this is the first report in literature found association between bilirubin and diabetic regulation.

In conclusion, low serum bilirubin levels in type 2 diabetic subjects should alert physicians for worse regulation. In addition to HbAlc measurement, evaluation of serum bilirubin may be useful in follow up of diabetic population.

\section{Funding}

None

\section{Conflict of interest}

None to declare

\section{References}

1. Jorgensen ME, Torp-Pedersen C, Finer N, Caterson I, James WP, et al. (2014) Association between serum bilirubin and cardiovascular disease in an overweight high-risk population from the SCOUT trial. Nutr Metab Cardiovasc Dis 24: 656-662. [Crossref]

2. Schwertner HA, Jackson WG, Tolan G (1994) Association of low serum concentration of bilirubin with increased risk of coronary artery disease. Clin Chem 40: 18-23. [Crossref]

3. Kimm H, Yun JE, Jo J, Jee SH (2009) Low serum bilirubin level as an independent predictor of stroke incidence: a prospective study in Korean men and women. Stroke 40: 3422-3427. [Crossref]

4. Breimer LH, Wannamethee G, Ebrahim S, Shaper AG (1995) Serum bilirubin and risk of ischemic heart disease in middle-aged British men. Clin Chem 41: 1504-1508. [Crossref]

5. Rantner B, Kollerits B, Anderwald-Stadler M, Klein-Weigel P, Gruber I, et al. (2008) Association between the UGT1A1 TA-repeat polymorphism and bilirubin concentration in patients with intermittent claudication: results from the CAVASIC study. Clin Chem 54: 851-857. [Crossref]

6. Tanaka M, Fukui M, Tomiyasu K, Akabame S, Nakano K, et al. (2009) Low serum bilirubin concentration is associated with coronary artery calcification (CAC) Atherosclerosis 206: 287-291. [Crossref]

7. Vitek L, Jirsa M, Brodanova M, Kalab M, Marecek Z, et al. (2002) Gilbert syndrome and ischemic heart disease: a protective effect of elevated bilirubin levels. Atherosclerosis 160: 449-456. [Crossref]

8. Yang H, Jin X, Kei Lam CW, Yan SK (2011) Oxidative stress and diabetes mellitus. Clin Chem Lab Med 49: 1773-1782. [Crossref]

9. Wolff SP (1993) Diabetes mellitus and free radicals. Free radicals, transition metals and oxidative stress in the aetiology of diabetes mellitus and complications. Br Med Bull 49: 642-652. [Crossref]

10. Giugliano D, Ceriello A, Paolisso G (1996) Oxidative stress and diabetic vascular complications. Diabetes Care 19: 257-267. [Crossref]

11. McDonagh AF (2010) The biliverdin-bilirubin antioxidant cycle of cellular protection: Missing a wheel? Free Radic Biol Med 49: 814-820. [Crossref]

Copyright: (C2018 Erkus E. This is an open-access article distributed under the terms of the Creative Commons Attribution License, which permits unrestricted use, distribution, and reproduction in any medium, provided the original author and source are credited. 